\title{
Religião evangélica e suas respostas às mulheres: aborto, direito e prosperidade
}

DoI

http://dx.doi.org/10.11606/ 2179-0892.ra.2017.141655

\author{
Nina Rosas \\ - Universidade Federal de Minas Cerais / Belo Horizonte, MG, Brasil \\ $\boldsymbol{\nabla}$ rosasnina@gmail.com
}

\begin{abstract}
TEIXEIRA, Jacqueline
Moraes. 2016. A mulher universal: corpo, gêneroe pedagogia da prosperidade. Rio de Janeiro, Mar de ideias-Navegação Cultural. 215 pp.
\end{abstract}

Por que há tantas mulheres em comunidades evangélicas? Por que há agremiações que apresentam discurso conservador em relação aos gêneros e às sexualidades e, a despeito disso, contam com mais de $70 \%$ de mulheres em sua audiência? Ainda não são muitas as obras socioantropológicas que tentam desvendar o teor das aflições femininas e o porquê de as igrejas conseguirem oferecer respostas tão satisfatórias a elas (Machado, 2005). 0 livro de Jacqueline Moraes Teixeira, longe de ser apenas um estudo de caso sobre corpo e gênero na Igreja Universal do Reino de Deus - IURD (embora só por isso já tivesse seu valor), certamente se tornará uma leitura obrigatória para a compreensão do modo como as mulheres experimentam, na religião, oportunidades que não necessariamente lhes seriam oferecidas por outros atores e contextos sociais (Woodhead, 2002). A literatura especializada já tem se inflexionado nos últimos anos, deixando de lado, a gosto ou contragosto, os ideais feministas e a avaliação da subordinação feminina em termos de perdas e ganhos, que serviram de referência para as análises pioneiras. Atualmente se tem rumando para a compreensão dos dogmas religiosos em si, e não como "etapa estratégica de um devir social" (Mafra, 1998: 227). A mulher universal: corpo, gênero e pedagogia da prosperidade se encaixa neste quadro, nos fornecendo ricas descrições e interpretações sobre o processo de construção dos valores de uma das mais expressivas igrejas evangélicas do Brasil.

O livro é uma rica etnografia que inclui inumeráveis idas a campo, participação em diversos rituais da Igreja, leitura de reportagens, revistas e livros, além de acompanhamento de programas televisivos. Bem embasada, a obra 
se embrenha da lógica da vida em abundância, da prosperidade, percebida sobretudo nos discursos do líder Edir Macedo em favor do aborto, e na produção e no reforço de certas práticas de gênero, entre as quais se inclui o planejamento familiar. Em termos de método, o que realmente salta aos olhos é a compreensão que os discursos são, na verdade, prática. Essa ideia é evocada pelo pensamento habermasiano, no qual o "mundo da vida" - esfera da comunicação, da produção simbólica de significados-é a base a partir da qual se constituem os entendimentos e as demandas da esfera pública. De modo complementar adota-se o pressuposto bourdieusiano de que "um determinado conjunto de práticas são compartilhadas como habitus no cotidiano dos frequentadores da IURD" (: 41); habitus este que é interiorizado e externalizado. Assim, de maneira engenhosa, entrega-se uma saída para um problema tão apontado nos estudos de religião, a saber, o da discrepância entre o discurso da liderança eclesiástica (recorte deveras privilegiado nas análises) e a vivência dos fiéis quanto a esses mesmos discursos.

No primeiro capítulo, com base na perspectiva de Cyril Lemieux sobre a relação performática da controvérsia (interação entre dois opositores e uma plateia), a autora traça o cenário sobre como o aborto induzido é tratado a partir das lógicas de planejamento familiar e prosperidade. Em seguida é trazida a dimensão do aborto como categoria jurídica. O recorte privilegia o histórico que mostra como a proibição da prática, isto é, o controle gerenciador dos corpos, era domínio do Estado e não da Igreja Católica. É chamada a atenção para o fato de que, na reforma constitucional de 1934, o aborto não era uma questão levantada nem pelo movimento feminista, que se preocupava com o sufrágio das mulheres e com mudanças nas leis que regiam o casamento civil (entre outros), nem mesmo para os religiosos, cujo foco era a busca da preservação dos direitos concedidos à Igreja Católica no período monárquico. Teixeira nos mostra é que só na década de 1980 que emergem novos argumentos sobre o ato. Desse modo, ela aciona um "quadro de controvérsias sobre o aborto" para apresentar o ponto de vista de Macedo, para quem a interrupção voluntária da gestação está associada ao risco de vida da mãe, aos casos de abandono infantil, ao planejamento familiar e à diminuição da violência no país, revelando a relação entre pobreza e expectativa de vida. Segundo essa construção, o aborto se torna, assim, parte do processo de gerenciamento humano sobre o nascimento. A IURD, ao apoiar o direito da mulher sobre seu corpo faz referência "a uma noção muito específica de direito (...) que está fortemente relacionada à Teologia da Prosperidade (TP)" (: 81). Em função de o embrião e o feto serem considerados "vida em abstração", o aborto é posto como uma medida racional de emprego da fé.

Ao seguir esse percurso, o livro contribui para a literatura especializada 
explorando outra dimensão da vida em abundância pregada pela TP que não a do dinheiro como mediador ritual. Para a autora, as categorias que estão em circulação nesse caso são as de sacrifício, desafio, perseverança e aprendizado. Em suas próprias palavras, elas "apontam para a produção de uma pedagogia da prosperidade" (: 96), que "pode ser observada principalmente no corpo de práticas que integra uma espécie de programa disciplinador baseado nos direitos reprodutivos" (: 97). Teixeira aposta no fato de que a família é o principal locus de prática e reformulação das noções de prosperidade e vida em abundância' ${ }^{1}$. Também, o estudo aponta para o incentivo dado pelo IURD à vasectomia e à família sem filhos e, nesse sentido, a mulher aparece como gerenciadora dos métodos contraceptivos, fortalecendo-se dentro do modelo nuclear.

A autora chama a atenção ainda para uma nova fase na produção do repertório simbólico da igreja, a saber, a da produção de livros direcionados a mulheres, mas que são produzidos especificamente por mulheres. Neles, o casamento é apresentado como foco da vida, a sexualidade e a sensualidade são voltadas e limitadas ao matrimônio, e rejeitam-se os valores feministas e as conquistas deste movimento a partir de um conjunto de prescrições que visam ensinar o que é ser mulher. Desse modo, novamente se aciona a noção de fé racional, que pretende fortalecer o espírito e disciplinar o corpo.

O raciocínio acima descrito abre caminho para o segundo capítulo do livro, dedicado a tratar de modo ainda mais específico dos discursos e das práticas relativas ao corpo da mulher, elaborados a partir das já conhecidas categorias mobilizadas pela Universal ao evocar a metáfora da guerra - "perseguição", "revolta", "sacrifício/desafio" e "conquista" (: 118). Nesse sentido, volta-se à exploração da campanha Fogueira Santa de Israel, a fim de evidenciar que mais que um contrato entre aquele que deseja algo e quem pode satisfazer o anseio, trata-se de uma "educação voltada para o direito à prosperidade" (: 127). Nos discursos das mulheres, a noção de prosperidade aparece como cuidado de si. $O$ ato de sacrifício diz respeito ao corpo, que se torna foco do trabalho, alvo de investimento pessoal e ação empreendedora do público feminino. Em suma, o corpo - e não só o dinheiro - se apresenta como dispositivo central na relação entre o fiel e a divindade.

Em seguida, descortina-se a divisão sexual do trabalho que caracteriza as disposições hierárquicas da Universal. Mostra-se a diferença entre servir no átrio (dar suporte aos frequentadores dos cultos) e no altar (posição destinada às mulheres que se casam com pastores e bispos) para chegar à explicação do desenvolvimento (nas mulheres) do "domínio prático das regras de polidez", capaz de "inculcar um estilo de vida voltado para a prosperidade" (:143). Apesar de várias mulheres protagonizarem esse processo pedagógico, destaca-se a filha de Edir Macedo, Cristiane Cardoso, criadora do programa Codllywood. A iniciativa de Cardoso é
1 Encontrei algo semeIhante sobre as noções de prosperidade compartilhadas na Igreja quando tratei das obras sociais realizadas na sede da Universal de Belo Horizonte, ocasião na qual chamei de ethos empreendedor disciplinado a disponibilidade e a diligência dos fiéis na execução de tarefas eclesiásticas. Notei que a doação daqueles indivíduos não se dava apenas no que tange à contribuição financeira; tratava-se de tempo. Vi ainda que a concepção de sucesso não se restringia à aquisição de bens materiais, mas também (e em alguns casos principalmente) à diferenciação de uns para com os outros e à consequente ascensão aos postos de poder da denominação (Rosas, 2012) 
descrita em detalhes, tendo como principal intuito a educação das mulheres no cultivo de sua aparência (postura, peso, roupas) e o incentivo a que ajudem as pessoas a sua volta, equilibrando os afazeres eclesiásticos e domésticos, e tendo determinação e coragem para enfrentar as dificuldades. O foco é a construção de "corpos prósperos" (: 191); trata-se de uma extensão dos rituais dos cultos para desafios e sacrifícios corporais realizados sistematicamente no cotidiano.

No último capítulo, vemos a autora, em diálogo com a literatura que põe a mulher como mediadora entre as esferas familiar e religiosa, dar um passo adiante apostando que os mediadores da produção de sentido empregados na IURD são o corpo feminino (disciplinado) e a conjugalidade (que ganha bastante projeção entre esses religiosos). São exploradas as dinâmicas dos cultos Terapia do Amor e os ensinamentos dos programas-aulas de internet e televisão A Escola do Amor (e suas diversas atividades correlatas), de Cristiane e seu marido, Renato Cardoso, para evidenciar o treinamento da vida sentimental e a constituição do modelo de família "bem-sucedido". Nesse sentido, o casamento "à prova de divórcio" (para usar um termo nativo) é propagado pela Igreja como a base para o sucesso pessoal. A união estimulada é a que se dá entre pessoas de idade semelhante, baseada na "razão" e na inteligência, tendo o homem como líder e a mulher como submissa e gerenciadora, estimulando ambos a terem zelo com a aparência, morarem separado dos demais familiares, manterem frequência nos intercursos sexuais e cultivarem interesses profissionais semelhantes. É com Foucault que Teixeira termina a interpretação desses dados, evocando o processo no qual a conjugalidade emergiu como "necessidade intrínseca" (: 186), através da qual se produzem regulações do corpo e da sexualidade e papéis para homens e mulheres na sociedade.

Desde o início, a leitura deste livro suscita o pensamento sobre a posição diferenciada da IURD e a consequente heterogeneidade dos evangélicos, o que, em função do acúmulo de debates sobre o tema das religiões nas ciências sociais brasileiras, não é de surpreender. Entretanto, dou destaque a isso por pensar que tal fato deveria ser ponto de partida de qualquer investigação, como se propôs Teixeira. $O$ trabalho da autora também tem o mérito de não reduzir as estratégias da Universal à busca por mais visibilidade, adesão feminina e oposição à Igreja Católica, ainda que-deve-se frisar - estes elementos tampouco devam ser ignorados. Há ainda um ganho qualitativo na obra ao se acionar a interpretação da esfera pública como locus de produção de sentido no qual igrejas, atores religiosos diversos e argumentos morais circulam com complexidade, articulando definições, como a do que é religioso e do que é legítimo (incluindo, neste caso, o aborto). O texto traz Habermas e a proposição de "fundamentar as pretensões de validade levantadas na ação comunicacional" (: 35$)$, o que se encaixa como uma luva para compreender os esforços de significação discursiva 
e as ações, ainda fique evidente que a tarefa de operacionalizar as categorias habermasianas nem sempre é razoável.

Ao tratar do aborto e do universo que concerne às mulheres, o livro nos apresenta um quadro distinto do traçado pela literatura da década de 1990-e não perde tempo apontando as diferenças com trabalhos anteriores. Ao contrário, recupera momentos relevantes que constituem a memória e a história da IURD, mas atualizando a produção socioantropológica a respeito das dinâmicas de uma igreja que vem se reinventando a fim de persistir nos dias atuais. Nesse sentido, Teixeira retoma muitas das doutrinas que compõem a racionalidade, ou os modos de compreensão da realidade suscitados pela Universal, o que acaba por tornar a obra uma porta de entrada autossuficiente que permite o acesso de um público de não especialistas às interpretações acadêmicas, sem que se incorra em erros fundamentais. Para um leitor mais experiente, todavia, as peculiaridades da etnografia sobre a educação do corpo da mulher é que se configuram como o objeto de interesse.

A relação entre corpo e sacrifício, disciplina e empreendedorismo de si é a grande contribuição original. Esta não deve ser lida, no entanto, sem a observação de que a profissão majoritária entre as fiéis (esteticistas, cabelereiras) não é só função da educação do corpo feminino, mas é um viés de classe; afinal, é comum a mulheres de camadas mais populares (público da Universal) a inserção no mercado de trabalho via profissões que requerem baixos níveis de treinamento e que tenham alta empregabilidade.

Por fim, é possível pensar os achados de Teixeira evocando o pensamento da feminista Angela McRobbie (2015), que, revisando noções de Butler e Foucault, nos lembra que o senso comum feminino atual passa a se caracterizar pela busca da "boa vida", do "ter tudo", isto é, do conquistar sucesso profissional, doméstico/familiar e sexual; ideia de perfeição que repousa na restauração de uma feminilidade tradicional. Para McRobbie, a ênfase na autogestão feminina nada mais é que um controle ainda mais exato e intensificado da sociedade sobre as mulheres, que toma a forma de autorregulação, refletindo uma perspectiva que se generalizou na contemporaneidade, a saber, a de que investir na beleza corporal é uma escolha pessoal, um zelo, reflexo do amor próprio (e no caso, do divino). Sem querer fixar como únicas referências as críticas feministas e seus ideais, cabe interpretar o livro A mulher universal à luz dessa tendência, aclarando que o novo trazido pela IURD ressoa valores mais abrangentes. A Universal pode ser vista, portanto, como mais uma amostra de que determinadas igrejas e religiões ofertam um espaço no qual se ensina e reforça um mecanismo de autorregulação², que aflora como uma maneira de controlar o corpo feminino na sociedade de consumo, mas - insisto -, oferecendo às mulheres certas "recompensas", ou, no mínimo, algumas ambições pelas quais se crê valer a pena lutar.
2 Ver, por exemplo, o modo como isso acontece entre as mulheres que se dedicam à assistência na IURD (Santos e Rosas, 2013) e entre as fiéis da Igreja Batista da Lagoinha (Rosas e de Castro, 2014). 
Nina Rosas é professora adjunta da UFMC. Possui mestrado e doutorado em Sociologia, tendo realizado estágio sanduíche no Center for Religion and Civic Culture. É autora do livro As obras sociais da Igreja Universal, e atualmente pesquisa e publica sobre evangélicos, corpo, gênero e sexualidade.

\section{REFERÊNCIAS BIBLIOGRÁFICAS}

MACHADO, Maria D. D. C.

2005 "Representações e relações de gênero nos grupos pentecostais". Revista de Estudos Feministas, v. 13, n. 2: 387-396.

MAFRA, Clara

1998 "Cênero e estilo eclesiástico entre os evangélicos". In AL, R. C. F. (org.). Novo nascimento: os evangélicos em casa, na igreja e na política. Rio de Janeiro, Muad, pp.224-250.

\section{MCROBBIE, Anagela}

2015 "Notes on the Perfect: Competitive Femininity in Neoliberal Times". Australian Feminist Studies, v. 30, n. 83: 3-20.

ROSAS, Nina

2012 "As ações sociais da Igreja Universal: recrutamento e empreendedorismo no A Cente da Comunidade de Belo Horizonte". Ciencias Sociales y Religión/ Ciências Sociais e Religião, v. 14, n. 17: 27-51.

ROSAS, Nina e DE CASTRO, Cristina M.

2014 "Charismatic Protestantism, Gender and Sexuality in Brazil". In SHIPLEY, H. et al. (orgs.). Clobalized Religion and Sexual Identity: Contexts, Contastations, Voices. Leiden, Brill, pp.217-235.

SANTOS, Yumi G. D. e ROSAS, Nina

2014 "Les Femmes dans les nouvelles politiques sociales et l'assistance néopentecôtiste: Possibilités d'émancipation ou reproduction des inégalités?". Brésil(s). Sciences humaines et sociales, v. 6: 75-97. 
RESENHA | Nina Rosas| Religião evangélica e suas

322

respostas às mulheres: aborto, direito e prosperidade

WOODHEAD, Linda.

2002 "Mulheres e gênero: uma estrutura teórica". REVER-Revista de Estudos da Religião, v. 1: 1-11. 